\title{
QUALIDADE DO SONO EM UNIVERSITÁRIOS NO CONTEXTO DA PANDEMIA DA COVID-19: um olhar multifatorial
}

DOI: 10.22289/2446-922X.V8N1A7

\author{
Laura Carvalho de Camargo ${ }^{1}$ \\ Natália Carvalho de Camargo \\ Romes Bittencourt Nogueira de Sousa \\ Luiz Henrique Alves Costa \\ Ana Gabriella Pereira Alves \\ Fagner Medeiros Alves \\ Maria Sebastiana Silva
}

\section{RESUMO}

A pandemia da COVID-19 veio acompanhada de prejuízos no emocional, nos hábitos alimentares e na atividade física. Os universitários ficaram incertos em relação à vida acadêmica, com a paralisação de atividades presenciais nas universidades. O estudo objetivou comparar o perfil (estados emocionais, atividade física e hábitos alimentares) de universitários com a autopercepção de qualidade do sono afetada pela pandemia (QSA) com aqueles com autopercepção de qualidade de sono não afetada (n-QSA) no contexto da pandemia da COVID-19. Entre 01/2021 a 04/2021, os discentes da Universidade Federal de Goiás preencheram, via ferramenta online, uma adaptação do questionário Convid-Pesquisa de Comportamentos. 173 discentes responderam esse instrumento. Os dados foram tabulados e organizados, os indivíduos foram divididos em dois grupos: o QSA (103) e o n-QSA (70), e a comparação foi feita entre os dois por meio do teste T de Student e teste do $\times 2$. Para a significância, o critério adotado foi $p<0,05$. O grupo QSA apresentou maior procura por atendimento em saúde mental $\left(0,0431^{*}\right)$, maior autopercepção de elevada ansiedade/nervosismo $\left(0,0095^{*}\right)$, tristeza $\left(0,0040^{*}\right)$, e isolamento afetivo $\left(0,0038^{*}\right)$ na pandemia. $O$ grupo QSA também apresentou menor nível de prática de atividade física $\left(0,0306^{*}\right)$, durante a pandemia. Ademais, o grupo QSA apresentou menor frequência de consumo de alimentos integrais, antes da COVID-19, do que o grupo n-QSA. Isso indicou maior acometimento nos estados emocionais do grupo QSA. É importante bons hábitos para uma saúde adequada.

Palavras-chave: Estudantes; Saúde Mental; Ritmo Circadiano.

\section{SLEEP QUALITY IN COLLEGE STUDENTS IN THE CONTEXT OF THE COVID-19 PANDEMIC: a multifactorial look}

\section{ABSTRACT}

The pandemic of COVID-19 was accompanied by losses in emotional, eating habits, and physical activity. University students were uncertain about their academic life, with the paralyzation of face-

\footnotetext{
${ }^{1}$ Endereço eletrônico de contato: laucarvalhodecamargo@gmail.com

Recebido em 26/11/2021. Aprovado pelo conselho editorial para publicação em 10/01/2022.
} 
to-face activities in universities. The study aimed to compare the profile (emotional states, physical activity and eating habits) of university students with self-perception of sleep quality affected by the pandemic (QSA) with those with self-perception of unaffected sleep quality ( $n-Q S A)$ in the context of the COVID-19 pandemic. Between 01/2021 and 04/2021, students at the Universidade Federal de Goiás completed, via an online tool, an adaptation of the questionnaire Convid-Pesquisa de Comportamentos. 173 students answered this instrument. Data were tabulated and organized, individuals were divided into two groups: the QSA (103) and the n-QSA (70), and comparison was made between the two using Student's t-test and $\times 2$ test. For significance, the criterion adopted was $p<0.05$. The QSA group showed higher demand for mental health care $\left(0.0431^{*}\right)$, higher selfperception of high anxiety/nervousness $\left(0.0095^{\star}\right)$, sadness $\left(0.0040^{*}\right)$, and affective isolation $\left(0.0038^{*}\right)$ in the pandemic. The QSA group also had a lower level of physical activity $\left(0.0306^{*}\right)$ during the pandemic. Furthermore, the QSA group had a lower frequency of whole food consumption before COVID-19 than the n-QSA group. This indicated greater impairment in the emotional states of the QSA group. Good habits are important for proper health.

Keywords: Students; Mental Health; Circadian Rhythm.

\section{CALIDAD DEL SUEÑO EN ESTUDIANTES UNIVERSITARIOS EN EL CONTEXTO DE LA PANDEMIA: una visión multifactorial}

\section{RESUMEN}

La pandemia de COVID-19 se acompañó de pérdidas emocionales, de hábitos alimenticios y de actividad física. Los universitarios se mostraron inseguros en su vida académica, con la paralización de las actividades presenciales en las universidades. El estudio pretendía comparar el perfil (estados emocionales, actividad física y hábitos alimentarios) de los estudiantes universitarios con autopercepción de calidad de sueño afectada por la pandemia (QSA) con aquellos con autopercepción de calidad de sueño no afectada ( $\mathrm{n}-\mathrm{QSA}$ ) en el contexto de la pandemia COVID19. Entre el 01/2021 y el 04/2021, los estudiantes de la Universidade Federal de Goiás completaron, vía herramienta online, una adaptación del Cuestionario Convid - Encuesta de Comportamientos. 173 estudiantes respondieron a este instrumento. Los datos se tabularon y organizaron, los individuos se dividieron en dos grupos: el QSA (103) y el n-QSA (70), y se realizó la comparación entre ambos mediante la prueba $T$ de Student y la prueba $\times 2$. Para la significación, el criterio adoptado fue $\mathrm{p}<0,05$. El grupo QSA presentó una mayor demanda de atención de salud mental $\left(0,0431^{\star}\right)$, una mayor autopercepción de alta ansiedad/nerviosidad $\left(0,0095^{\star}\right)$, tristeza $\left(0,0040^{*}\right)$ y aislamiento afectivo $\left(0,0038^{*}\right)$ en la pandemia. El grupo QSA también mostró un menor nivel de práctica de actividad física $\left(0,0306^{*}\right)$, durante la pandemia. Además, el grupo QSA tenía una menor frecuencia de consumo de alimentos integrales antes de la COVID-19 que el grupo n-QSA. Esto indica una mayor implicación en los estados emocionales del grupo QSA. Los buenos hábitos son importantes para una buena salud.

Palabras clave: Estudiantes; Salud Mental; Ritmo Circadiano.

\section{INTRODUÇÃO}

A COVID-19 consiste em uma doença infecciosa provocada pelo vírus SARS-CoV-2. Essa doença foi relatada primeiramente na cidade de Wuhan, na Província de Hubei na China, no mês de dezembro de 2019, mas ainda não se pode determinar o local de origem com exatidão. No dia 
11 de março de 2020, a Organização Mundial de Saúde (2020) declarou a doença como uma pandemia (Almeida et al., 2020). Esta provocou diversas alterações na rotina dos seres humanos, com o emprego de medidas de restrição para evitar a propagação da doença, como o distanciamento social por exemplo, além do distanciamento dos familiares, e a ausência de contato físico com as pessoas (Almeida et al., 2020). Consequentemente, houve a presença de estados emocionais de ansiedade, nervosismo, estresse, tristeza, isolamento afetivo e prejuízo na qualidade do sono, podendo prejudicar inclusive o sistema imune (Silva, Ono, et al., 2020; Tempesta et al., 2018; Voitsidis et al., 2020).

O sono constitui um mecanismo periódico e fisiológico do organismo, no qual há uma menor reação à estímulos externos, sendo regulado pela liberação de melatonina pela glândula pineal (Gomes et al., 2010). O sono faz parte do ciclo sono-vigília, sendo que este sofre regulação do ritmo circadiano e é controlado pelos núcleos supraquiasmáticos do hipotálamo (Fukushige et al., 2014; Gomes et al., 2010; Saper et al., 2005; Schwartz \& Kilduff, 2015). De acordo com estudo de Marelli et al. (2021), houve uma piora da qualidade do sono durante a pandemia da COVID-19 em participantes da Itália, incluindo estudantes universitários e funcionários, com maior impacto observado nos estudantes.

No contexto da pandemia da COVID-19, questões como a qualidade do sono devem ser avaliadas. A qualidade do sono pode ser avaliada por meio de componentes objetivos como: latência do sono, frequência que o indivíduo acorda durante a noite e eficiência do sono. Entretanto, neste trabalho foi avaliado a autopercepção da qualidade do sono, uma autoavaliação feita pelos próprios indivíduos (Ohayon et al., 2017). A qualidade do sono pode refletir as diferentes experiências que cada indivíduo relata ter em relação ao sono (Krystal \& Edinger, 2008).

Uma boa qualidade de sono é responsável por regular os estados emocionais e aspectos psicológicos dos indivíduos (Walker, 2009). Ao contrário, uma qualidade de sono ruim está associada significativamente com altos níveis de ansiedade e depressão, sendo que essa situação está muito presente nos universitários, prejudicando seu estado emocional e até o desempenho acadêmico (Evans et al., 2021; Norbury \& Evans, 2019).

Em um estudo com discentes de uma faculdade da Índia, Ghrouz et al. (2019) indicaram que uma qualidade de sono ruim foi significativamente associada com níveis mais elevados de a ansiedade e a depressão. Ademais, os participantes que apresentaram pior qualidade do sono tinham 1,39 vezes mais chance de apresentar ansiedade. Os alunos de universidade, principalmente os de graduação, sofrem de muito estresse e ansiedade, até porque estão em uma fase de transição para a vida adulta, que requer maior independência e capacidade de lidar com as situações do cotidiano (Eisenberg et al., 2007; Mackean, 2011; Verger et al., 2009).

A ansiedade consiste em uma reação emocional preparatória, adaptativa a situações estressantes e até futuras (Freitas, 2020). Entretanto, o problema está quando ela ocorre de forma 
excessiva e com uma intensidade muito alta, podendo se tornar um Transtorno de Ansiedade. $O$ estresse também pode levar à ansiedade por meio dos mecanismos do eixo hipotálamo-hipófiseadrenal, além da participação do sistema nervoso autônomo, sobretudo em sua porção simpática (Silva, Goulart et al., 2018). Já a tristeza é um sintoma da depressão, mas os dois não são a mesma coisa, uma vez que a depressão é considerada um transtorno de humor (Freitas, 2020).

Segundo Barros et al. (2020), no contexto da pandemia, 40,4\% dos participantes brasileiros adultos reportaram se sentirem frequentemente tristes ou deprimidos, 52,6\% relataram se sentirem frequentemente ansiosos ou nervosos. Quanto ao sono, 43,5\% reportaram início de problemas de sono durante a pandemia, enquanto $48,0 \%$ reportaram já possuírem problemas de sono antes da pandemia, que se agravou com ela. Dessa forma, é importante procurar atendimento em saúde mental quando necessário, a fim de prevenir uma piora dos estados emocionais e possível desenvolvimento de um transtorno.

Outro fator que pode influenciar o sono é a alimentação, ou seja, o que o ser humano consome de alimentos pode afetar o ritmo circadiano e a qualidade do sono. Neste sentido, há estudos que mostram que alguns nutrientes induzem a produção de melatonina, um neurotransmissor relacionado à melhora do sono (Marins et al., 2020). A melatonina repassa ao sistema nervoso informações sobre o ciclo de luz e escuridão. Dentre os precursores de neurotransmissores que podem agir sobre o sono está o aminoácido triptofano (Irwin et al., 2016; Peuhkuri et al., 2012a; Zhao et al., 2020).

Os alimentos integrais são ricos em micronutrientes, e alguns podem conter o aminoácido triptofano, que é precursor da serotonina, que por sua vez é precursora da melatonina, importante hormônio influenciador do sono (Bravo et al., 2013; Mohajeri et al., 2015; Valim et al., 2017). Vitaminas do complexo B são micronutrientes importantes para controlar a ansiedade e melhorar a saúde mental, uma vez que participam da produção de neurotransmissores (Freitas, 2020; Shabbir et al., 2013). Neste sentido, o hábito alimentar adequado ajuda na boa saúde mental e bons estados emocionais, além de contribuir para melhora da qualidade do sono (Freitas, 2020).

Os alimentos integrais são formados por cereais, como milho, arroz, trigo, centeio, cevada e aveia, além das frutas e legumes (Ornelas, 2007). Os grãos integrais, que compõem os alimentos integrais, não passam por um processo de refinamento, e mantêm intactos o endosperma (amido), o gérmen, a casca, estes dois ricos em nutrientes e contendo também minerais, mesmo se os grãos tiverem sido moídos. Nos alimentos integrais há a preservação do valor nutricional do grão inteiro e do alimento original (American Association of Cereal Chemists International, 1999; Food and Drug Administration 2006; Haas, 2007). Os grãos integrais possuem maior quantidade de fibras, vitaminas e minerais, importantes para um sono adequado (Ferruzzi et al., 2014; Seal et al., 2016).

No contexto da pandemia da COVID-19, cerca de $1 / 3$ dos poloneses entrevistados não consumiam vegetais e frutas frescas todos os dias, enquanto $1 / 3$ consumia doces todos os dias, 0 
que demonstra um hábito alimentar não saudável. Isso pode contribuir para a diminuição da ingestão de vitaminas necessárias ao organismo (Sidor \& Rzymski, 2020).

Ainda sobre a qualidade do sono, há indícios de que a prática de atividades físicas e exercícios físicos aumenta o sono de ondas lentas, aumenta o tempo total de sono, diminui a latência para o início do sono, e melhora qualidade do sono. As atividades físicas também melhoram aspectos emocionais e atuam nos âmbitos motivacionais, cognitivos e comportamentais dos indivíduos, levando a um sono melhor (Mello, 2013).

No contexto da COVID-19, é essencial a manutenção da prática de exercícios físicos, pois além de evitar o surgimento de doenças, como cardiovasculares e respiratórias, protegendo contra a COVID-19 em si, previne o surgimento de transtornos psiquiátricos, uma vez que o distanciamento social pode provocar os estados emocionais de ansiedade, nervosismo, tristeza e de isolamento afetivo, que em excesso podem ser prejudiciais (Matias \& Dominski, 2020).

Ademais, as medidas de distanciamento social podem ter prejudicado a prática de atividade física, apesar desta ser essencial para manter uma boa saúde física e mental. O recomendado pelo Ministério da Saúde é de pelo menos 150 minutos por semana de atividade física aeróbica de intensidade moderada, ou pelo menos 75 minutos por semana de atividade física aeróbica de intensidade vigorosa, ou até mesmo uma mistura de atividade física de intensidade moderada e vigorosa (Ministério da Saúde, 2021).

Nesse contexto pandêmico, muitas vezes a qualidade de vida e bem-estar dos indivíduos são prejudicados. O bem-estar consiste pela satisfação de necessidades psicológicas, sociais, culturais, espirituais, materiais, e biológicas, com sua vida e estados emocionais (Keyes, 2006; Nogueira, 2017). A qualidade de vida consiste na percepção que cada pessoa tem em relação à posição na vida, influenciada por valores, pela cultura, pela saúde física e psicológica, por crenças, por relações pessoais, por suas expectativas e metas, apreensões, comportamentos, emoções, além da percepção dos outros em relação ao indivíduo (The WHOQOL Group, 1995). No caso dos universitários, muitos já possuíam uma renda baixa, dificuldade de acesso à internet, e até falta de materiais como computadores, e isso tornou ainda mais complexa a pandemia, uma vez que muitos estudantes tiveram dificuldades para acompanhar as aulas remotas, ademais muitos perderam seus empregos. Isso tudo afeta o psicológico dos indivíduos, o que também piora a qualidade de vida e o bem-estar deles (Santos, 2021).

Os universitários são um grupo vulnerável, pois são muito impactados no âmbito do sono e dos estados emocionais devido à demanda e à pressão acadêmica. A vulnerabilidade consiste na relação entre a intensidade do dano e a magnitude de uma ameaça ou risco potencial (Bertolozzi et al., 2009). A vulnerabilidade psicológica é caracterizada por crenças e cognições danosas, tanto em relação à percepção de si mesmo quanto na interação com outros indivíduos, interpretando uma situação de maneira distorcida, e isso tudo prejudica as emoções, as relações sociais, e o bem- 
estar (Nogueira, 2017). Os universitários são um grupo vulnerável, com a influência de vários fatores: condições sociodemográficas como a idade, ainda mais na transição para a vida adulta; residência; nível socioeconômico; desempenho acadêmico. Por exemplo: ficar longe da família pode torná-los vulneráveis à depressão (Nogueira, 2017). Com a pandemia da COVID-19 essa vulnerabilidade se exacerbou com a presença do aumento do medo e do estresse, e a presença da ansiedade, tristeza, e isolamento afetivo (Carvalho \& Silveira, 2021).

Devido ao cenário pandêmico e os seus reflexos sobre a saúde mental dos estudantes, as universidades estão criando e amplificando medidas para o atendimento e o acompanhamento em relação à saúde mental, como por exemplo o Programa Saudavelmente, criado pela Pró-Reitoria de Assuntos Estudantis (PRAE) pela Universidade Federal de Goiás.

Dessa forma, no contexto da pandemia da COVID-19, a procura por atendimento em saúde mental, a autopercepção de estados emocionais, a prática atividade física e os hábitos alimentares estão alterados em indivíduos com a qualidade do sono afetada pela pandemia em comparação à indivíduos com a qualidade do sono não afetada.

Mediante o exposto, e contextualizando o estudo à realidade dos estudantes da Universidade Federal de Goiás, o objetivo deste estudo foi comparar o perfil (procura por atendimento em saúde mental, estados emocionais, hábitos alimentares e atividade física) de universitários com a qualidade do sono afetada com aqueles com a qualidade de sono não afetada no contexto da pandemia da COVID-19.

\section{MATERIAIS E MÉTODOS}

Este trabalho é um estudo transversal que faz parte de um projeto matriz "Da Infância à Maturidade: Investigando o Desenvolvimento Humano Sob uma Perspectiva Psicobiológica e Evolutiva", submetido e aprovado pelo Comitê de Ética (CEP) da Universidade Federal de Goiás, sob parecer n.4.767.509, de acordo com os termos das Resoluções n 466/2012 do Conselho Nacional de Saúde. Uma Revisão Narrativa foi realizada mediante a pesquisa de artigos no PubMed e no Google Acadêmico. O questionário foi compartilhado da seguinte maneira: por meio de um formulário eletrônico ele foi enviado para a coordenação dos cursos que reencaminhou para seus alunos de graduação por e-mail ou mediante sites oficiais da Universidade Federal de Goiás, sendo preenchido online utilizando-se a ferramenta Google Forms entre janeiro e abril de 2021, no contexto da pandemia da COVID-19. Foram incluídos no estudo universitários que concordaram em participar e assinaram o Termo de Consentimento Livre e Esclarecido.

\subsection{Características da Amostra}

Rev. Psicol Saúde e Debate. Jan., 2022:8(1): 97-124. 
Neste estudo foram adotados alguns critérios de exclusão, são eles: repetições de preenchimento; indivíduos com idade inferior a 18 anos; indivíduos que marcaram a opção de resposta sexo indefinido (devido ao pouco número de respostas nesta opção); e indivíduos que responderam a opção "Eu já tinha problemas de sono, mas eles diminuíram" na pergunta "A pandemia afetou a qualidade do seu sono?", em razão da baixa quantidade de respostas nesta opção. Foram incluídos estudantes universitários de 18 anos ou mais de idade, da Universidade Federal de Goiás (UFG), tanto de licenciaturas quanto de bacharelados. Assim, foram analisados 173 estudantes universitários, sendo $\cong 43,9 \%$ do sexo masculino e $\cong 56,1 \%$ do sexo feminino, com idade média de $24,54 \pm 6,25$ anos.

\subsection{Procedimentos e Instrumentos}

O instrumento utilizado foi o Questionário Convid - Pesquisa de Comportamentos (ICICT/FIOCRUZ, 2020), desenvolvido pela Fundação Oswaldo Cruz e o Instituto de Comunicação e Informação Científica e Tecnológica em Saúde (ICICT), em parceria com a Universidade Federal de Minas Gerais (UFMG), e a Universidade Estadual de Campinas (UNICAMP), e foi adaptado para este estudo.

\subsubsection{Avaliação da autopercepção da qualidade do sono}

O sono foi avaliado considerando a seguinte pergunta do questionário: "A pandemia afetou a qualidade do seu sono?"

As opções de resposta para esta pergunta foram "Não afetou, continuo dormindo bem"; "Comecei a ter problemas de sono"; "Continuei tendo os mesmos problemas de sono"; "Eu já tinha problemas de sono e eles pioraram bastante".

As opções "Comecei a ter problemas de sono" e "Eu já tinha problemas de sono e eles pioraram bastante" foram consideradas como autopercepção de qualidade do sono afetada pela pandemia, e as alternativas "Não afetou, continuo dormindo bem" e "Continuei tendo os mesmos problemas de sono" foram consideradas como autopercepção de qualidade do sono não afetada pela pandemia.

\subsubsection{Avaliação da autopercepção de estados emocionais}

A saúde mental (entendida como estados emocionais de isolamento afetivo, tristeza e ansiedade/nervosismo) foi avaliada pelas perguntas "No período da pandemia, com que frequência você se sentiu isolado(a) dos seus familiares ou amigos próximos?", "No período da pandemia, com 
que frequência você se sentiu triste ou deprimido(a)?"; e "No período da pandemia, com que frequência você se sentiu ansioso(a) ou nervoso(a)?"

As opções de resposta foram "Nunca, Poucas vezes, Muitas vezes, Sempre". Tais questões foram baseadas no World Health Survey - Brazil (2003), como citado em Szwarcwald et al. (2005).

As opções "Nunca" e "Poucas vezes" foram agrupadas nas denominações "Baixa ansiedade/nervosismo, Baixa tristeza e Baixo isolamento afetivo", enquanto as opções "Muitas vezes" e "Sempre" foram agrupadas nas denominações "Elevada ansiedade/nervosismo, elevada tristeza e elevado isolamento afetivo".

\subsubsection{Avaliação do autorrelato dos hábitos alimentares}

Os hábitos alimentares foram avaliados considerando o consumo dos seguintes alimentos ou grupos de alimentos: Verduras/legumes crus ou cozidos; Frutas; Feijão; Alimentos integrais (pães, arroz, biscoitos, macarrão, grãos integrais, aveia, granola, linhaça); Presunto, salame, mortadela, salsicha, linguiça ou hamburguer; Pizza congelada ou lasanha congelada ou outro prato pronto congelado; Salgadinhos "de pacote" (Ex. Ruffles, Cheetos, Fandangos); Chocolates, biscoitos doces, pedaços de torta. As perguntas foram: "Quanto à sua alimentação: Usualmente, antes da pandemia, em quantos dias da semana costumava comer esses alimentos?"; "Durante a pandemia, você passou a comer esses alimentos em quantos dias da semana?". Para cada alimento ou grupo foi questionado a frequência de consumo na semana, antes e durante a pandemia: 1 dia ou menos; de 2 a 4 dias; e 5 dias ou mais.

\subsubsection{Motivo para procura em atendimento de saúde}

Sobre o motivo de atendimento de saúde foi considerada a pergunta "Qual o principal motivo para você ter procurado atendimento de saúde?"

As opções de resposta foram: "Suspeita do novo coronavírus ou infecção respiratória; Doença ou outro problema de saúde; Continuação de tratamento ou terapia; Consulta pré-natal; Parto; Problema de saúde mental; Problema odontológico; Lesão provocada por acidente doméstico; Lesão por acidente de trânsito ou outro tipo de acidente; Lesão provocada por agressão ou outra violência; e não se aplica".

\subsubsection{Autorrelato de prática de atividade física}

Quanto à prática de atividade física foi considerada a seguinte pergunta: "Antes da pandemia do novo coronavírus, quantos dias por semana você praticava algum tipo de exercício físico ou 
esporte? (não considere fisioterapia)"; e "Durante a pandemia do novo coronavírus, quantos dias por semana você pratica/praticava exercício físico ou esporte?”. As opções para essas perguntas foram: "Menos de um dia por semana, 1 a 2 dias, 3 a 4 dias, 5 ou mais dias".

Para a interpretação, as opções "Menos de um dia por semana" e "1 a 2 dias" foram agrupadas em "Baixa atividade física", e as opções "3 a 4 dias" e " 5 ou mais dias" foram agrupadas em "Elevada atividade física".

\subsection{Análises Estatísticas}

Os dados foram tabulados e organizados em planilhas do Excel 2007 (Microsoft, 2007). As análises estatísticas foram feitas por meio do software Biostat 2008 5.0.1. (Analystsoft,2008). Os estudantes foram divididos em dois grupos: aqueles com autopercepção de qualidade do sono afetada pela pandemia (103) e os com autopercepção de qualidade do sono não afetada pela pandemia (70). Realizou-se a análise descritiva para a obtenção dos valores da média e do desvio padrão. Os dados absolutos foram comparados entre os grupos por meio do T de Student (teste de comparação entre amostras de dois grupos em valores absolutos), e os categóricos pelo teste do $x^{2}$ (Teste do Qui-Quadrado). O critério de significância adotado foi $p<0,05$ ( $p$-valor - nível de significância inferior à 0,05).

\section{RESULTADOS E DISCUSSÃO}

Na tabela 1, são apresentados os dados sociodemográficos da amostra estudada, assim como os $p$ valores das diferenças entre grupos.

Tabela 1 - Dados sociodemográficos

\begin{tabular}{|c|c|c|c|c|}
\hline Variável & Características & Sono afetado (103) & $\begin{array}{c}\text { Sono não afetado } \\
(70)\end{array}$ & $\mathrm{p}$ \\
\hline Sexo & & $40,8 \%(\mathrm{M})$ & $48,6 \%(\mathrm{M})$ & 0,3106 \\
\hline$(\mathrm{M} / \mathrm{F})$ & & $59,2 \%(F)$ & $51,4 \%(F)$ & \\
\hline $\begin{array}{l}\text { Idade } \\
\text { (anos) }\end{array}$ & & $24,49 \pm 6,44$ & $24,61 \pm 6,00$ & 0,9025 \\
\hline \multirow{2}{*}{$\begin{array}{l}\text { Cor ou } \\
\text { raça }\end{array}$} & Branca (\%) & 44,7 & 51,4 & 0,3815 \\
\hline & Parda (\%) & 26,2 & 30,0 & 0,5851 \\
\hline
\end{tabular}

Rev. Psicol Saúde e Debate. Jan., 2022:8(1): 97-124. 


\begin{tabular}{|c|c|c|c|c|}
\hline & Preta (\%) & 26,2 & 14,3 & 0,0603 \\
\hline & Amarela (\%) & 1,9 & 2,9 & 0,6941 \\
\hline & Indígena (\%) & 1,0 & 1,4 & 0,7822 \\
\hline \multirow[t]{2}{*}{ Peso $(\mathrm{Kg})$} & Antes da pandemia & $69,91 \pm 17,36$ & $70,9 \pm 17,17$ & 0,6935 \\
\hline & Durante a pandemia & $72,41 \pm 18,35$ & $71,81 \pm 17,06$ & 0,8299 \\
\hline Altura (m) & & $1,67 \pm 0,09$ & $1,70 \pm 0,09$ & 0,1014 \\
\hline
\end{tabular}

FONTE: autores (2021); Legenda: $\mathrm{p}<0,05$, *estatisticamente significativo.

$\mathrm{Na}$ tabela 2, tabela 3 e tabela 4 são expressos os dados relativos à comparação entre grupos para vários parâmetros, dentre os quais: procura por atendimento em saúde mental, autopercepção de saúde mental (estados emocionais), autorrelato de prática de atividade física, e autorrelato de hábitos alimentares respectivamente.

Os resultados mostraram que pessoas com a qualidade do sono afetada pela pandemia (QSA) apresentaram de forma estatisticamente significativa maior procura por atendimento de saúde por problema de saúde mental, maior autopercepção de elevada ansiedade/nervosismo, de elevada tristeza e de elevado isolamento afetivo, enquanto o oposto foi observado naqueles que afirmaram não ter a qualidade do sono afetada pela pandemia ( $n-Q S A)$, conforme a tabela 2. Em relação aos outros motivos para procura em atendimento de saúde, no contexto da pandemia, não houve diferença entre os grupos QSA e n-QSA.

Tabela 2 - Comparação entre QSA e n-QSA em relação aos estados emocionais e procura por atendimento em saúde mental

\begin{tabular}{ccccc}
\hline Variável & & $\begin{array}{c}\text { Sono afetado } \\
(\text { QSA })(103)\end{array}$ & $\begin{array}{c}\text { Sono não } \\
\text { afetado } \\
\text { (n-QSA) (70) }\end{array}$ & p \\
\hline $\begin{array}{c}\text { No contexto da } \\
\text { COVID-19 }\end{array}$ & $\begin{array}{c}\text { Procura por } \\
\text { atendimento em } \\
\text { Saúde Mental } \\
\text { (\%) }\end{array}$ & 8,7 & 1,4 & $0,0431^{*}$ \\
Estados & $\begin{array}{c}\text { Baixa } \\
\text { ansiedade/ }\end{array}$ & 9,7 & 24,3 & $0,0095^{*}$ \\
emocionais no & & & \\
\hline
\end{tabular}

Rev. Psicol Saúde e Debate. Jan., 2022:8(1): 97-124. 
contexto da nervosismo (\%)

COVID-19

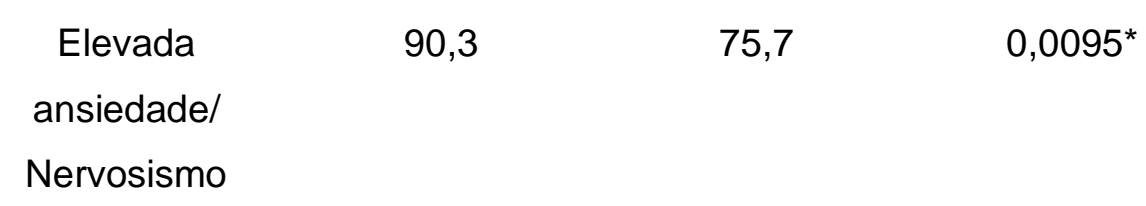

(\%)

$\begin{array}{cccc}\begin{array}{c}\text { Baixa tristeza } \\ (\%)\end{array} & 15,5 & 34,3 & 0,0040^{*} \\ \begin{array}{c}\text { Elevada tristeza } \\ (\%)\end{array} & 84,5 & 65,7 & 0,0040^{*} \\ \begin{array}{l}\text { Baixo } \\ \text { isolamento } \\ \text { afetivo (\%) }\end{array} & 16,5 & 35,7 & 0,0038^{*} \\ \text { Elevado } & & & \\ \text { isolamento } \\ \text { afetivo (\%) }\end{array}$

15,5

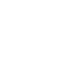

FONTE: autores (2021); Legenda: $p<0,05$, *estatisticamente significativo

O grupo QSA apresentou de forma estatisticamente significativa menor nível de atividade física no contexto da pandemia da COVID-19, enquanto o oposto foi observado no grupo n-QSA, conforme a tabela 3.

Tabela 3 - Comparação entre QSA e n-QSA em relação à atividade física

\begin{tabular}{ccccc}
\hline Variável & & $\begin{array}{c}\text { Sono afetado } \\
\text { (QSA) (103) }\end{array}$ & $\begin{array}{c}\text { Sono não } \\
\text { afetado } \\
\text { (n-QSA) (70) }\end{array}$ & $\mathrm{p}$ \\
\hline $\begin{array}{c}\text { Atividade física } \\
\text { antes da } \\
\text { pandemia da } \\
\text { COVID-19 }\end{array}$ & $\begin{array}{c}\text { Baixa atividade } \\
\text { física (\%) }\end{array}$ & 53,4 & 42,9 & 0,1734 \\
& $\begin{array}{c}\text { Elevada } \\
\text { atividade física }\end{array}$ & 46,6 & 57,1 & 0,1734 \\
\hline
\end{tabular}

Rev. Psicol Saúde e Debate. Jan., 2022:8(1): 97-124. 
$(\%)$

\begin{tabular}{|c|c|c|c|c|}
\hline & Baixa atividade & 76,7 & 61,4 & $0,0306^{*}$ \\
\hline no contexto da & física (\%) & & & \\
\hline$D-19$ & Elevada & 23,3 & 38,6 & $0,0306^{*}$ \\
\hline
\end{tabular}

(\%)

FONTE: autores (2021); Legenda: $p<0,05$, *estatisticamente significativo

Em relação à alimentação, o grupo QSA apresentou uma frequência menor de consumo de alimentos integrais antes da pandemia, do que o grupo n-QSA, de forma estatisticamente significativa. Antes da pandemia, o n-QSA consumia alimentos integrais com uma frequência maior do que o grupo QSA, pois enquanto este consumia de 2 a 4 dias por semana, o grupo $n-Q S A$ consumia com uma frequência mais elevada (em 5 dias ou mais por semana), conforme tabela 4. Contudo, não houve diferença em relação aos alimentos integrais entre os grupos QSA e n-QSA durante a pandemia. Não houve diferença entre os grupos QSA e n-QSA para os outros grupos alimentares, tanto antes da pandemia quanto no contexto da pandemia.

Tabela 4 - Comparação entre QSA e n-QSA em relação aos hábitos alimentares

\begin{tabular}{|c|c|c|c|c|}
\hline Variável & & $\begin{array}{l}\text { Sono afetado } \\
\text { (QSA) (103) }\end{array}$ & $\begin{array}{c}\text { Sono não } \\
\text { afetado } \\
\text { (n-QSA) (70) }\end{array}$ & $p$ \\
\hline $\begin{array}{c}\text { Hábitos } \\
\text { alimentares } \\
\text { antes da } \\
\text { pandemia da } \\
\text { COVID-19 }\end{array}$ & $\begin{array}{c}\text { Baixo consumo } \\
\text { de alimentos } \\
\text { integrais } \\
\text { (1 dia ou } \\
\text { menos/ } \\
\text { semana) (\%) } \\
\text { Médio consumo } \\
\text { de alimentos } \\
\text { integrais (2 a } 4 \\
\text { dias/semana) } \\
\text { (\%) }\end{array}$ & 36,9 & 21,4 & $0,0303^{*}$ \\
\hline
\end{tabular}




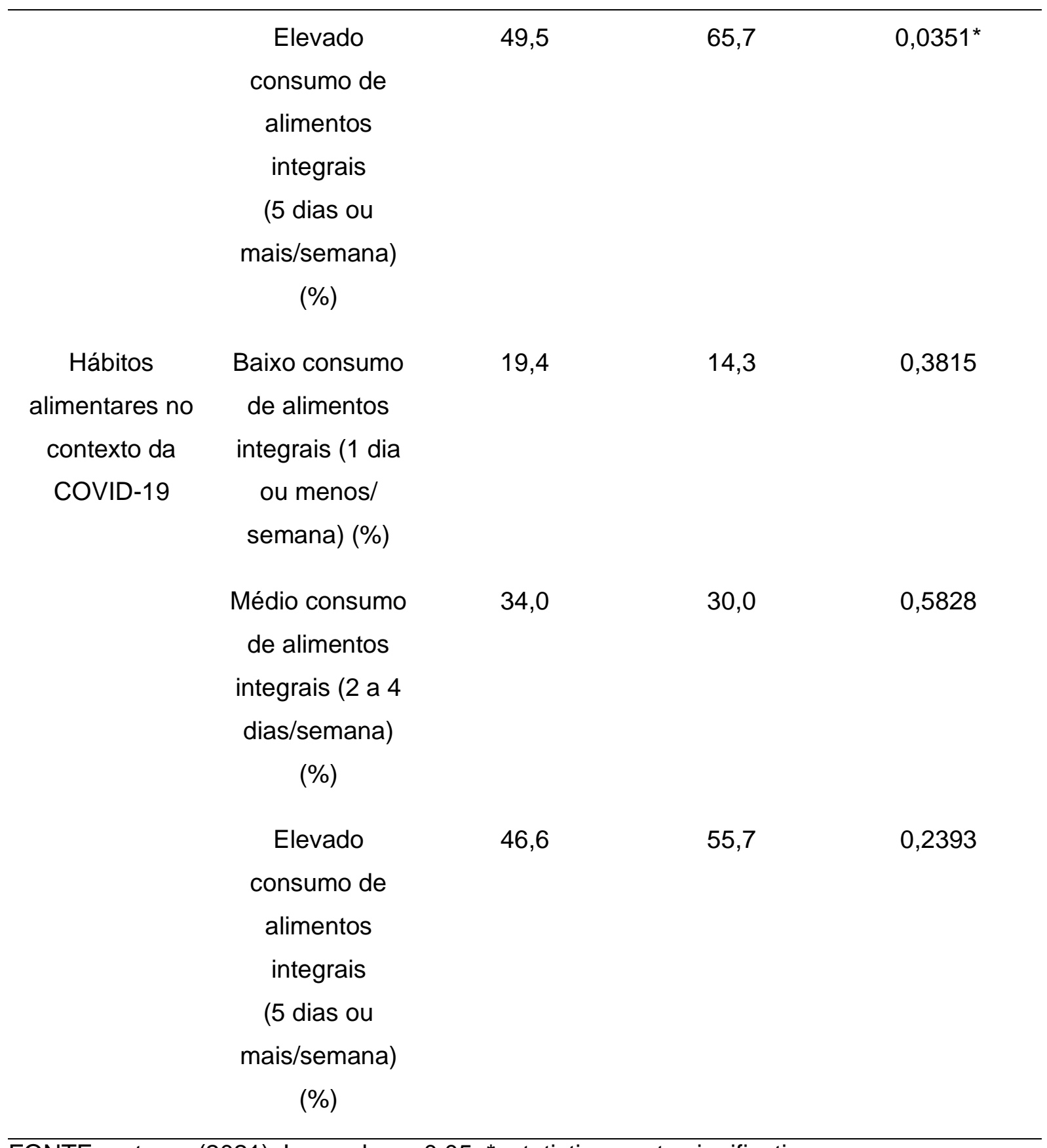

FONTE: autores (2021); Legenda: $p<0,05$, *estatisticamente significativo

\subsection{Sono e saúde mental (Estados Emocionais)}

Os resultados obtidos neste trabalho confirmam a hipótese de que procura por atendimento em saúde mental e a autopercepção de estados emocionais estão alterados no grupo com qualidade do sono afetada pela pandemia comparado ao grupo com qualidade do sono não afetada pela pandemia. O grupo QSA apresentou maior procura por atendimento em saúde mental e níveis mais elevados de ansiedade/nervosismo, tristeza e isolamento afetivo do que o grupo n-QSA. Isso revela que pessoas com a qualidade do sono afetada apresentaram estados emocionais mais impactados no contexto da COVID-19. 
Os resultados mostram um possível prejuízo na saúde mental nos indivíduos com a qualidade do sono afetada pela pandemia. Isso é analisado também por outros autores. Nesta linha, Stanton et al. (2020), durante a pandemia da COVID-19, encontraram em 40,7\% dos voluntários australianos uma mudança negativa para o sono. Essa mudança do sono para uma qualidade ruim foi associada significativamente com maiores chances de níveis elevados de depressão, ansiedade e estresse.

Um estudo sobre ansiedade, tristeza e isolamento afetivo no contexto da COVID-19, de Malta et al., (2020), encontraram que $41,2 \%$ dos brasileiros se sentiram isolados muitas vezes, $41,3 \%$ se sentiram ansiosos muitas vezes, e 35,2\% se sentiram tristes ou deprimidos muitas vezes.

Inúmeros aspectos podem contribuir para isso, como a preocupação com a situação financeira, medo de se contaminar, contaminar amigos e familiares, provocando a expressão das emoções. As emoções, pelo olhar da psicologia evolucionista, podem ser adaptativas até certo ponto, pois foram selecionadas para protegerem os indivíduos. A ansiedade, por exemplo, preparou os ancestrais dos seres humanos para lutar ou fugir de uma situação de perigo ou potencial perigo, e pode estar presente até os dias atuais, em situações, por exemplo, como medo de não conseguir acompanhar os estudos da universidade em uma situação de pandemia, podendo contribuir para a antecipação de fatos na mente e organização dos comportamentos dos indivíduos (Freitas, 2020). Já a tristeza é considerada uma emoção natural dos indivíduos, acontecendo em situações de perda tanto de uma pessoa próxima quanto devido a outros fatores como perda de liberdade, emprego e renda. Mas, deve-se estar atento para essas emoções não se tornarem em excesso, portanto mal adaptativas, o que pode levar ao desenvolvimento de psicopatologias (Del Giudice, 2014; Freitas, 2020; Nesse \& Williams, 1997).

Estudo conduzido com universitários dos Estados Unidos, mostrou que eles se sentiam isolados $(2,67 \pm 1,07)$, ansiosos $(2,67 \pm 1,04)$, tristes $(2,44 \pm 0,88)$, deprimidos $(2,37 \pm 1,06)$, e apresentavam distúrbios do sono $(2,48 \pm 1,01)$, com a presença de sono agitado, revelando o impacto da pandemia nesse grupo da sociedade. Por meio da análise de correlação, constatou-se que a preocupação de se infectar com o vírus estava associada positiva e significativamente com sintomas da saúde mental ( $r=0.248 ; p \leq 0.001$ ) (Tasso et al., 2021).

Os universitários merecem atenção, uma vez que fazem parte de um grupo propenso à prejuízos na saúde mental, nos hábitos alimentares e no sono. Os universitários já eram um grupo muito vulnerável psicologicamente, devido a essa fase de transição para a vida adulta e novas responsabilidades. Durante a pandemia, a vulnerabilidade exacerbou, pois as aulas que anteriormente eram presenciais passaram a ocorrer de forma remota, muitos estudantes que trabalhavam perderam seus empregos, alguns voltaram para a sua cidade natal e outros tiveram que enfrentar a pandemia sem a presença da família, muitos perderam sua renda, e passaram pela situação de insegurança alimentar, que já existia antes e que piorou no contexto pandêmico 
(Carvalho \& Silveira, 2021). As incertezas sobre a vida acadêmica e universitária, além da suspensão das atividades sociais presenciais, não podendo encontrar os amigos, provavelmente impactou aspectos emocionais dos estudantes, deixando esse grupo ainda mais vulnerável (Pan, 2020; Tasso et al., 2021). O problema do ensino remoto foi que muitos estudantes não possuíam acesso à internet ou à internet de qualidade desde antes da pandemia, muitas vezes devido à vulnerabilidade socioeconômica, e isso pode ter contribuído para o aumento do estresse durante o contexto pandêmico.

Esse contexto difícil da pandemia, acompanhado da percepção da ameaça da doença, tédio, frustração, podem aumentar o nível de estresse, e levar a estados emocionais como tristeza e ansiedade. Se esses estados emocionais ultrapassarem a capacidade de lidar com a situação, podem levar ao desenvolvimento de um transtorno (Pérez-Fuentes et al., 2020).

Quando um indivíduo apresenta estresse e ansiedade pode haver presença de maior funcionamento do eixo hipotálamo-hipófise-adrenal, com consequente aumento de cortisol no plasma, urina e líquido cefalorraquidiano, dificultando a qualidade do sono, podendo prejudicar também a saúde mental (Saraiva et al., 2013). Ademais, pode haver maior produção de noradrenalina e adrenalina, deixando o indivíduo em alerta.

$\mathrm{Na}$ literatura, outros estudos também evidenciam o papel do sono na saúde mental e viceversa, mas também trazem a influência das telas de computador e celular. Werneck et al., (2020), encontraram durante a pandemia da COVID-19 piora da qualidade do sono e a associação desta com a inatividade física, elevado uso de aparelhos eletrônicos, ansiedade, nervosismo, tristeza, depressão, e isolamento afetivo. A utilização de computadores e celulares próximo da hora de dormir pode prejudicar a qualidade do sono, uma vez que a luminosidade das telas pode inibir a produção e liberação de melatonina. Isso é ainda mais preocupante no contexto da COVID-19, na qual os universitários passaram a utilizar mais o computador e o celular em razão das aulas remotas e online (Carone et al., 2020; Jniene et al., 2019; Richter et al., 2020).

A literatura acerca desses assuntos ainda está em construção no Brasil, com inúmeras contribuições pela Fundação Oswaldo Cruz, e outras instituições universitárias. Entretanto, ainda é necessária mais pesquisa na área, principalmente focando no grupo de estudantes universitários.

O dano à saúde mental, no contexto da pandemia, também é evidenciado no estudo de Almeida et al. (2020), no qual 3,4\% das pessoas procuraram atendimento por problemas de saúde mental.

\subsection{Sono, saúde mental (Estados Emocionais) e hábitos alimentares}

Os hábitos alimentares também se encontram alterados no grupo de qualidade do sono afetada pela pandemia em comparação com o grupo de qualidade do sono não afetada pela 
pandemia, uma vez que o grupo QSA apresentou consumo de alimentos integrais em menos dias por semana, antes da pandemia, do que o grupo n-QSA.

A literatura tem apresentado relação entre alimentos integrais, ricos em vitaminas, minerais, com redução dos níveis de ansiedade e melhora da saúde mental em indivíduos saudáveis (Silva, 2020). Alguns alimentos integrais possuem o aminoácido triptofano, também importante para uma boa saúde mental. Em nosso estudo, de acordo com o relato dos participantes, tais alimentos foram consumidos mais frequentemente, antes da pandemia, por pessoas com qualidade do sono não afetada pela pandemia, o que sugere serem provavelmente alimentos protetores do sono, haja visto que também estão associados a redução dos níveis de ansiedade (Freitas, 2020).

No presente estudo, foi encontrado entre os universitários que a melhor qualidade do sono estava interligada com o consumo de alimentos integrais. Segundo estudo de Malta et al. (2021), durante a pandemia, com adultos residentes em Minas Gerais, houve diminuição do consumo de alimentos integrais, uma vez que passou de $49,6 \%$ para $42,7 \%$.

Os grãos integrais contêm camadas externas de tegumentos onde há concentração de minerais e vitaminas do complexo B e se encontra a fibra (Ornellas, 2007). As vitaminas do complexo B são necessárias para a síntese de neurotransmissores importantes para a manutenção de uma boa saúde mental e consequentemente para uma boa qualidade do sono (Aspy et al., 2018).

O triptofano é um aminoácido que necessita da ação da Piridoxal-fosfato (PLP), que é uma coenzima obtida a partir da vitamina B6. A PLP é importante para a síntese de neurotransmissores como serotonina e ácido gama-aminobutírico (GABA). Como o GABA exerce um grande papel em favorecer o sono e reduzir a ansiedade, um hábito alimentar adequado com alimentos contendo vitamina B6 pode melhorar a qualidade do sono (Nelson \& Cox, 2014; Shabbir et al., 2013; Zhao et al., 2020).

Para a produção de serotonina ocorrer é preciso de algumas vitaminas como a B3, B6, B12, B9 e minerais como magnésio, como demonstrados na Figura 1. As vitaminas B3, B6, B9 e outras do complexo B estão presentes em alimentos integrais (Freitas, 2020; Zanello, 2012). Conforme estudo de Harada et al. (2007), em japoneses, o consumo de alimentos contendo triptofano, no café da manhã, contribui para um bom ritmo diurno do tipo matinal e uma maior qualidade do sono à noite (Zhao et al., 2020).

A serotonina é um neurotransmissor que pode influenciar diversos fatores como o sono, o humor e a cognição, inclusive prevenindo transtornos de ansiedade, transtornos de humor e outros prejuízos na saúde mental e no estado emocional (Bravo et al., 2013). O mecanismo de ação da serotonina aumenta a vigília, mas é importante também para o sono Não - REM (NREM) (Imeri \& Opp, 2009; Zhao et al., 2020). Este neurotransmissor é precursor da produção de melatonina, produzida principalmente pela glândula pineal durante a noite, no escuro, e alterações nela podem prejudicar o sono (Bravo et al., 2013; Peuhkuri et al., 2012b). 
A homocisteína também pode exercer papel prejudicial na saúde mental. O acúmulo da homocisteína provoca danos nas funções cerebrais e consequentemente na saúde mental, uma vez que provoca prejuízos nas funções dos neurotransmissores, neurotoxicidade, estresse oxidativo, aumento de danos no DNA e de espécies reativas de oxigênio (ERO), diminuição do reparo do DNA, e a apoptose das células (Freitas, 2020). Para a depuração desse composto é preciso da ação de vitaminas do complexo $\mathrm{B}$, presentes nos alimentos integrais. Ademais, a vitamina $\mathrm{E}$ é antioxidante, diminuindo o estresse oxidativo no sistema nervoso central, e está presente no óleo de germe de trigo (Freitas, 2020; Silva, 2020).

Desde antes da pandemia, a insegurança alimentar é um fator de dificuldade na vida dos estudantes universitários. Muitos deles acabam indo morar sozinhos nessa fase da vida, o que dificulta a quantidade e qualidade da alimentação, uma vez que os gastos aumentam com a moradia e o sustento próprio, e inúmeros universitários possuem dificuldade em trabalhar e estudar ao mesmo tempo. Ademais, muitos estudantes universitários deixam de se alimentar de forma adequada devido à grande demanda de aulas e atividades acadêmicas, optando por comidas congeladas e não saudáveis, de rápido preparo. No contexto da pandemia da COVID-19, com o aumento da perda de renda e do desemprego, e a inflação, a situação piorou, além do fato de que houve o fechamento dos restaurantes universitários. Durante a pandemia, com o aumento da ansiedade, tristeza e estresse, pode ter havido a presença de uma alimentação inadequada, o que consequentemente prejudicou a saúde mental e a qualidade do sono (Alvim, 2021; Carvalho \& Araújo Silveira, 2021).

O grupo QSA apresentou consumo de alimentos integrais em menos dias por semana no período anterior a pandemia, do que o grupo de n-QSA, o que indica que a falta do consumo desses alimentos pode prejudicar o sono. 
A Figuras 1 demonstra a síntese de melatonina no organismo. A Figura 2 demonstra a relação dos fatores não-fóticos e fóticos com o núcleo supraquiasmático.

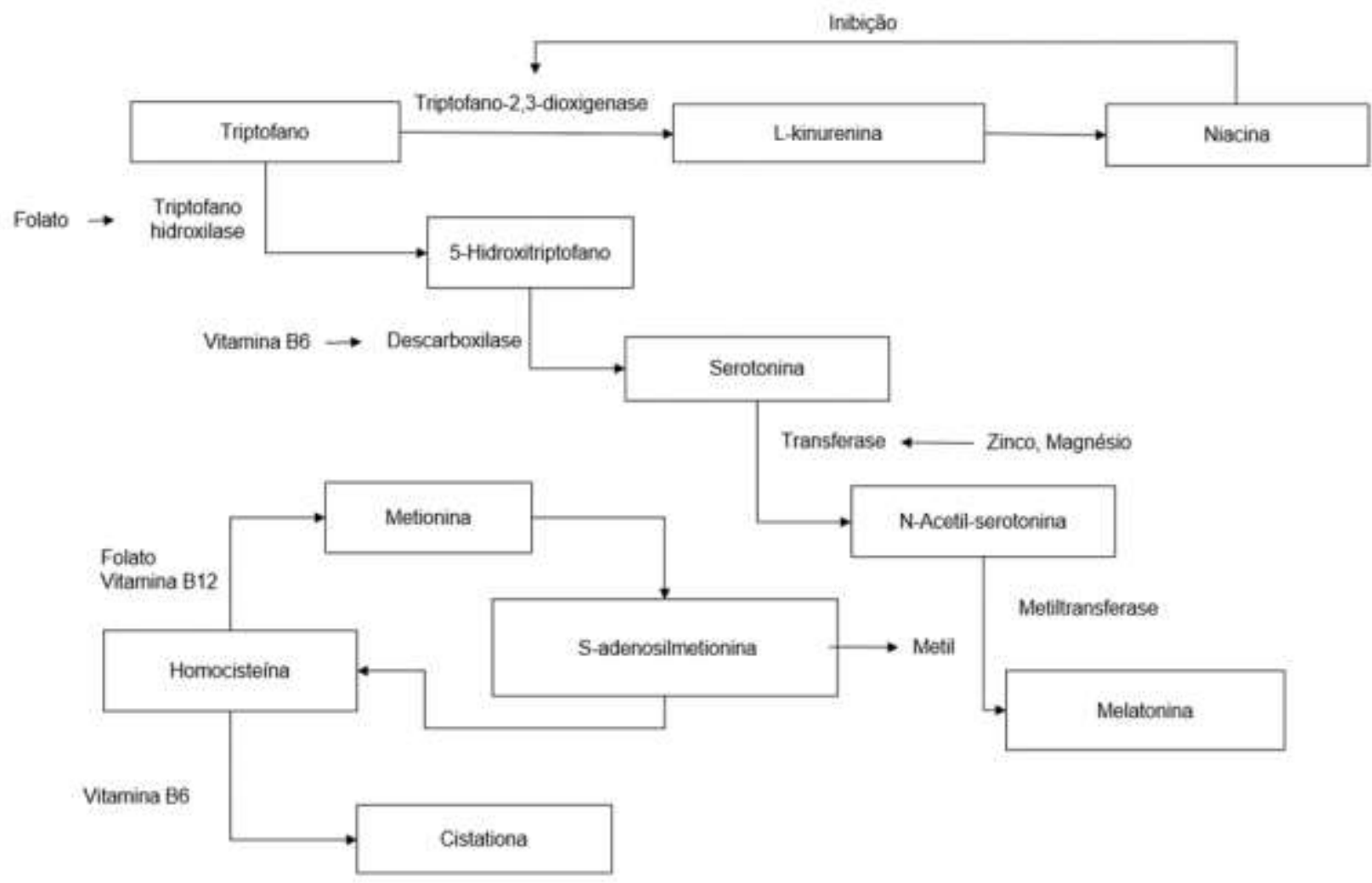

Figura 1. A via da síntese e o metabolismo da melatonina e atuação dos nutrientes. Fonte: autores (2021); Adaptado de Peuhkuri et al., (2012a, p.2) citado em Torres (2012).

Nìo Fóticos

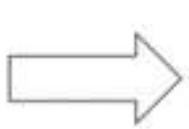

Núcleo Supraquiasmático

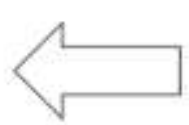

Fóticos

Figura 2. Relação dos fatores não-fóticos e fóticos com o núcleo supraquiasmático. Fonte: autores (2021); Adaptado de: Marins et al., (2020, p.3) a partir de informações de Peuhkuri et al., (2012b).

\subsection{Importância do sono}

O sono é composto por dois padrões: sono Não - REM (NREM), composto por três fases (ocorrendo recuperação fisiológica), e sono REM, sendo que o ciclo do sono começa depois da vigília relaxada e segue a seguinte sequência: Estágio N1, Estágio N2, Estágio N3, Estágio N2, sono REM, este último com a presença de movimento rápido dos olhos (Mello, 2013).

Os processos de vigília e do sono modulam a relação corpo-mente. Isso acontece da seguinte maneira: durante a vigília há muitas atividades cotidianas que exigem a atuação da Rev. Psicol Saúde e Debate. Jan., 2022:8(1): 97-124. 
cognição, do âmbito psicológico e do âmbito motor, o que gera o consumo de muita energia do corpo e da mente; enquanto que no sono há uma redução de consumo de energia, aumento dos processos de anabolismo com o objetivo de regenerar os tecidos, restauração do corpo, com a produção de proteínas, diminuição do consumo de oxigênio, da temperatura, diminuição da atividade muscular esquelética, cessação dos movimentos com propósito, maior ativação do sistema nervoso autônomo parassimpático, e o preparo do corpo e da mente para quando vier a próxima vigília (Mello, 2013). Entretanto, no sono REM, há a presença de ativação simpática periódica, consistindo quando o indivíduo sai do sono profundo, havendo o movimento dos olhos de forma rápida, uma respiração rápida, aumento da frequência cardíaca e da pressão arterial, e aumento da produção de cortisol, de forma a preparar o organismo para a vigília, sendo que nesta fase podem ocorrer os sonhos e é importante para a aprendizagem, e o homeostato emocional (Mello, 2013).

Inclusive, os sonhos e a memória são muito importantes para o equilíbrio emocional. A privação de sono pode levar à perda de memórias relacionadas com estímulos neutros e positivos, acentuando as memórias de estímulos negativos, provocando comportamentos agressivos e impulsivos, e leva à diminuição da expressividade facial quando exposto a estímulos emocionais (Anderson \& Platten, 2011; Mello, 2013; Walker, 2009).

O sono é importante para manter uma boa saúde física e mental nos seres humanos, melhorando a imunidade, aprendizagem, memória, cognição, autoestima, regulação emocional, comportamentos, resolução de problemas, o desempenho acadêmico, e preparar a mente para as atividades da vigília, que envolvem aspectos cognitivos e emocionais (Hosker et al., 2019). De acordo com outras pesquisas, como a de Walker (2009) a privação de sono pode prejudicar a atenção, afetar a memória e até levar a um humor depressivo.

A questão dos universitários é que pode haver uma desregulação do ciclo sono-vigília, uma vez que as atividades acadêmicas em excesso podem contribuir para uma quantidade de horas de sono reduzida e para alteração dos horários para padrões diferentes do ciclo claro-escuro, o que pode prejudicar a regulação emocional (Almondes \& Araújo, 2003). No contexto da pandemia da Covid-19, isso se exacerbou, não só devido ao aumento das demandas acadêmicas de forma online, em que os horários de estudos ultrapassaram para a noite, e a incerteza acadêmica, mas também devido ao medo de se infectar e infectar o próximo, o medo da perda de parentes queridos, o aumento do desemprego, diminuição das interações sociais presenciais, o que contribuiu para aumento da ansiedade e estresse (Carvalho \& Silveira, 2021).

\subsection{Sono e atividade física}

Rev. Psicol Saúde e Debate. Jan., 2022:8(1): 97-124. 
Em relação à prática de atividades físicas no contexto da COVID-19, Brito et al. (2021) encontraram que adultos jovens faziam significativamente menos atividade física do que os indivíduos mais velhos, sendo que $34,2 \%$ do grupo de indivíduos com menores idades não praticavam atividade física no contexto da pandemia. Além disso, $2 / 3$ da amostra relataram qualidade do sono irregular. Isso pode ser explicado devido à mudança de rotina provocada pela pandemia, que pode ter alterado também os horários de dormir e acordar, sendo que uma qualidade de sono ruim pode prejudicar a imunidade e regulação emocional (Almondes, 2020). Para amenizar essa consequência, é necessário apoio dos familiares para a prática de atividades físicas e exercícios físicos em casa, além de um acompanhamento online com um professor da área (Rhodes et al., 2001).

Em contrapartida, outros indivíduos podem ter passado a praticar atividades físicas e exercícios físicos para aproveitarem e poderem sair de suas casas. O que é inegável é a associação entre a prática de atividades físicas e a redução do sofrimento psicológico (Ashdown-Franks et al., 2019; Rodriguez-Ayllon et al., 2019; Stanton et al., 2020).

Há diversas hipóteses que podem explicar os benefícios do exercício físico na qualidade do sono e na saúde mental. Uma delas é a de que o exercício físico diminui o estado de ansiedade, o que contribui para um sono melhor (Mello, 2013). Existe também a hipótese monoaminérgica, na qual a prática de exercícios físicos melhora a transmissão sináptica aminérgica (de noradrenalina, dopamina e serotonina), o que pode melhorar o humor, entretanto é recomendado fazer exercícios físicos no final da tarde e não antes de dormir, porque pode deixar o indivíduo em alerta (Mello, 2013).

Para finalizar, segundo estudo de Blando et al., (2021), as maiores dificuldades relatadas pelos estudantes universitários no contexto da pandemia, sendo alunos de graduação foram: estabelecer uma rotina $(57,4 \%)$, lidar com procrastinação $(56,6 \%)$, praticar atividades físicas (47,6\%), estudar (46,9\%), cuidar da saúde mental (33,4\%) e manter hábitos alimentares (30,6\%). E as maiores dificuldades relatadas em relação à vida acadêmica dos universitários foram: os estudos e a saúde mental.

\subsection{Limitações do Estudo}

No geral, a principal limitação do estudo, devido ao fato de ter sido realizado durante a pandemia, foi a aplicação do questionário de forma online, o que retrata uma autopercepção do próprio indivíduo, o que pode causar viés nos resultados.

\section{CONSIDERAÇÕES FINAIS}


Os resultados obtidos por este estudo mostraram que os universitários com a qualidade de sono afetada pela pandemia (QSA) apresentaram maior procura por atendimento em saúde mental, e maior autopercepção de elevada ansiedade/nervosismo, de elevado isolamento afetivo e de elevada tristeza, do que o grupo de universitários com a qualidade de sono não afetada pela pandemia (n-QSA). Isso reflete o papel da qualidade do sono nos estados emocionais e vice-versa.

Universitários do grupo QSA também apresentaram menor frequência de consumo de alimentos integrais antes da pandemia do que o grupo de universitários n-QSA. Ademais, o grupo QSA apresentou menor nível de prática de atividade física no contexto da pandemia. Estes achados revelam o efeito protetor da atividade física e bons hábitos alimentares na qualidade do sono e na saúde mental.

Diante do contexto da COVID-19, é imprescindível manter uma boa saúde física e mental, ainda mais no grupo de universitários, que estão passando para a vida adulta, com incertezas amplificadas pela pandemia. Este trabalho, além de auxiliar na elaboração de trabalhos futuros, também contribuirá para que instituições, universidades e a sociedade criem medidas para minimizar o impacto da pandemia na vida dos estudantes e em pandemias futuras. Dessa forma, este estudo contribuirá para adoção de estratégias que ajudem os universitários.

Algumas medidas que podem ser adotadas são: criação pelas universidades de mais medidas de atendimento em saúde mental para seus estudantes, como por exemplo ampliando os horários de atendimento e a quantidade de profissionais da área disponíveis, cuidando assim dos estados emocionais deles; incentivo à atividade física levando aulas gratuitas à população em parques; e divulgação, em mídias oficiais das universidades, de bons hábitos alimentares e qualidade de sono.

Portanto, é preciso levar em conta a influência dos hábitos alimentares e da atividade física no sono e nos estados emocionais pela comunidade científica, ainda mais no contexto pandêmico que está sendo vivenciado, e o aumento da vulnerabilidade dos universitários, que já era elevada antes da pandemia.

Para futuros artigos, podem ser retratados de forma mais aprofundada os aspectos de gênero, raça e idade e suas variações entre os universitários e a influência na qualidade de vida deles.

Rev. Psicol Saúde e Debate. Jan., 2022:8(1): 97-124. 


\section{REFERÊNCIAS}

Analystsoft. (2008). BioStat 2008 5.0.1 [Software de computador]. Analystsoft. https://biostat.br.uptodown.com/windows

Almeida, W. S., Szwarcwald, C. L., Malta, D. C., Barros, M. B. A., Souza Júnior, P. R. B., Azevedo, L. O., Romero, D., Lima, M. G., Damacena, G. N., Machado, Í. E., Gomes, C. S., Pina, M. F., Gracie, R., Werneck, A. O., Silva, D. R. P. (2020). Mudanças nas condições socioeconômicas e de saúde dos brasileiros durante a pandemia de COVID-19. Revista Brasileira de Epidemiologia, 23 (14), E200105. https://doi.org/10.1590/1980-549720200105

Almondes, K. M, Araújo, J. F. (2003). Padrão do ciclo sono-vigília e sua relação com a ansiedade em estudantes universitários. Estudos de Psicologia, 8(1), 37-43. https://doi.org/10.1590/S1413-294X2003000100005

Almondes, K. M. (2020). Manejo das alterações de sono no contexto de enfrentamento da COVID19. Socie Bras de Psic, 8, 1-9.

American Association of Cereal Chemists International (1999). Whole grain definition. Cereal Foods World, 45 (79).

Anderson, C., Platten, C. R. (2011). Sleep deprivation lowers inhibition and enhances impulsivity to negative stimuli. Behavioural Brain Research, 217(2), 463-466. https://doi.org/10.1016/j.bbr.2010.09.020

Ashdown-Franks, G., Sabiston, C. M., Stubbs, B. (2019). The evidence for physical activity in the management of major mental illnesses: A concise overview to inform busy clinicians' practice and guide policy. Current Opinion in Psychiatry, 32(5), 375-380. https://doi.org/10.1097/YCO.0000000000000526

Aspy, D. J., Madden, N. A., Delfabbro, P. (2018). Effects of Vitamin B6 (Pyridoxine) and a B Complex Preparation on Dreaming and Sleep. Perceptual and Motor Skills, 125(3), 451462.003151251877032. https://doi.org/10.1177/0031512518770326

Alvim, Mariana. (2021). 'Ou ia para aula ou comia': como insegurança alimentar está prejudicando universitários brasileiros. [Página de site]. Retirado de https://www.bbc.com/portuguese/brasil59256787

Barros, M. B. A., Lima, M. G., Malta, D. C., Szwarcwald, C. L., Azevedo, R. C. S., Romero, D., Souza Júnior, P. R. B., Azevedo, L. O., Machado, Í. E., Damacena, G. N., Gomes, C. S., Werneck, A. O., Silva, D. R. P., Pina, M. F., Gracie, R. (2020). Relato de tristeza/depressão, nervosismo/ansiedade e problemas de sono na população adulta brasileira durante a pandemia de COVID-19. Epidemiologia e Serviços de Saúde, 29(4), 1-12, Artigo e2020427. https://doi.org/10.1590/s1679-49742020000400018

Bertolozzi, M. R., Nichiata, L. Y. I., Takahashi, R. F., Ciosak, S. I., Hino, P., Val, L. F., Guanillo, M. C. L. T. U., Pereira, E. G. (2009). Os conceitos de vulnerabilidade e adesão na Saúde Coletiva. Revista da Escola de Enfermagem da USP, 43, Esp2, 1326-1330. https://doi.org/10.1590/S0080-62342009000600031

Björck, I., Östman, E., Kristensen, M., Anson, N. M., Price, R. K., Haenen, G. R. M. M., Havenaar, R., Knudsen, K. E. B., Frid, A., Mykkänen, H., Welch, R. W., Riccardi, G. (2012). Cereal grains for nutrition and health benefits: Overview of results from in vitro, animal and human studies in 
the Healthgrain project. Trends in Food Science \& Technology, 25(2), 87-100. https://doi.org/10.1016/j.tifs.2011.11.005

Blando, A., Marcilio, F. C. P., Franco, S. R. K., Teixeira, M. A. P. (2021). Levantamento sobre dificuldades que interferem na vida acadêmica de universitários durante a pandemia de COVID19. Revista Thema, 20, 303-314. http://dx.doi.org/10.15536/thema.V20.Especial.2021.303314.1857

Bravo, R., Matito, S., Cubero, J., Paredes, S. D., Franco, L., Rivero, M., Rodríguez, A. B., \& Barriga, C. (2013). Tryptophan-enriched cereal intake improves nocturnal sleep, melatonin, serotonin, and total antioxidant capacity levels and mood in elderly humans. AGE, 35(4), 1277-1285. https://doi.org/10.1007/s11357-012-9419-5

Brito, L. M. S., Lima, V. A., Mascarenhas, L. P., Mota, J., Leite, N. (2021). Physical activity, eating habits and sleep during social isolation: from young adult to elderly. Revista Brasileira de Medicina do Esporte, 27, 21-25. https://doi.org/10.1590/1517-8692202127012020 0061

Carone, C. M. M., Silva, B. D. P., Rodrigues, L. T., Tavares, P. S., Carpena, M. X., \& Santos, I. S. (2020). Fatores associados a distúrbios do sono em estudantes universitários. Cadernos de Saúde Pública, 36(3), 1-16, e00074919. https://doi.org/10.1590/0102-311X00074919

Carvalho, C. J., Araújo Silveira, M. F. (2021). (Sobre) vivências, saúde mental e enfrentamento à pandemia de universitários em vulnerabilidade socioeconômica. Research, Society and Development, 10(14), e288101421955-e288101421955. http://dx.doi.org/10.33448/rsdv10i14.21955

Del Giudice, M. (2014). An Evolutionary Life History Framework for Psychopathology. Psychological Inquiry, 25(3-4), 261-300. https://doi.org/10.1080/1047840X.2014.884918

Eisenberg, D., Gollust, S. E., Golberstein, E., Hefner, J. L. (2007). Prevalence and Correlates of Depression, Anxiety, and Suicidality Among University Students. American Journal of Orthopsychiatry, 77(4), 534-542. https://doi.org/10.1037/0002-9432.77.4.534

Evans, S., Alkan, E., Bhangoo, J. K., Tenenbaum, H., Ng-Knight, T. (2021). Effects of the COVID19 lockdown on mental health, wellbeing, sleep, and alcohol use in a UK student sample. Psychiatry Research, 298, Artigo 113819. https://doi.org/10.1016/j.psychres.2021.113819

FDA guidance for industry and FDA staff (2006). Guidance on whole grainlabel statement; 2006. https://www.federalregister.gov/documents/2006/02/17/06-1509/draft-guidance-for-industryand-fda-staff-whole-grains-label-statements-availability

Ferruzzi, M. G., Jonnalagadda, S. S., Liu, S., Marquart, L., McKeown, N., Reicks, M., Riccardi, G., Seal, C., Slavin, J., Thielecke, F., van der Kamp, J.-W., Webb, D. (2014). Developing a Standard Definition of Whole-Grain Foods for Dietary Recommendations: Summary Report of a Multidisciplinary Expert Roundtable Discussion. Advances in Nutrition, 5(2), 164-176. https://doi.org/10.3945/an.113.005223

Freitas, F. F. (2020). Contribuições da Alimentação para a Prevenção da Ansiedade. In Lopes, F. A., Castro, F. N., Oliveira J. J. (organizadores), Temas em Evolução do Comportamento Humano (pp. 94-104). Mossoró, RN: EDUERNE.

Fukushige, H., Fukuda, Y., Tanaka, M., Inami, K., Wada, K., Tsumura, Y., Kondo, M., Harada, T., Wakamura, T., Morita, T. (2014). Effects of tryptophan-rich breakfast and light exposure during 
the daytime on melatonin secretion at night. Journal of Physiological Anthropology, 33(1), 33. https://doi.org/10.1186/1880-6805-33-33

Francisco, T. R. (2010). Alimentos Integrais e Mudanças de Hábitos Alimentares em Acadêmicos de um Curso de Nutrição, Criciuma, SC [Trabalho de Conclusão de Curso, Universidade do Extremo Sul Catarinense (UNESC)] Repositório UNESC. http://repositorio.unesc.net/bitstream/1/170/1/Thaise\%20Rosso\%20Francisco.pdf

Ghrouz, A. K., Noohu, M. M., Dilshad Manzar, Md., Spence, D. W., BaHammam, A. S., PandiPerumal, S. R. (2019). Physical activity and sleep quality in relation to mental health among college students. Sleep and Breathing, 23(2), 627-634. https://doi.org/10.1007/s11325-019$\underline{01780-z}$

Gibson-Smith, D., Bot, M., Brouwer, I. A., Visser, M., Giltay, E. J., \& Penninx, B. W. J. H. (2020). Association of food groups with depression and anxiety disorders. European Journal of Nutrition, 59(2), 767-778. https://doi.org/10.1007/s00394-019-01943-4

Gomes, M. M., Quinhones, M. S., Engelhardt, E. (2010). Neurofisiologia do sono e aspectos farmacoterapêuticos dos seus transtornos. Revista Brasileira de Neurologia, 46(1), 5-15. https://www.academia.edu/32258607/Neurofisiologia_do_sono_e_aspectos_farmacoterapeuti $\cos$

Harada, T., Hirotani, M., Maeda, M., Nomura, H., Takeuchi, H. (2007). Correlation between Breakfast Tryptophan Content and Morningness-Eveningness in Japanese Infants and Students Aged 0 15 yrs. Journal of PHYSIOLOGICAL ANTHROPOLOGY, 26(2), 201-207. https://doi.org/10.2114/jpa2.26.201

Haas, P. (2007). Efetividade da ingestão dos graõs integrais na prevenção do câncer colorretal: revisão sistemática de estudos de coorte com metanálise [Tese de doutorado, Florianópolis]. Repertório Institucional Universidade Federal de Santa Catarina. https://repositorio.ufsc.br/handle/123456789/89852

Hosker, D. K., Elkins, R. M., Potter, M. P. (2019). Promoting Mental Health and Wellness in Youth Through Physical Activity, Nutrition, and Sleep. Child and Adolescent Psychiatric Clinics of North America, 28(2), 171-193. https://doi.org/10.1016/..chc.2018.11.010

ICICT, Fiocruz (2020). ConVid - Pesquisa de Comportamentos. (https://convid.fiocruz.br/index.php?pag=questionario_adulto). DOI:10.7303/syn22250673.1

Imeri, L., Opp, M. R. (2009). How (and why) the immune system makes us sleep. Nature Reviews Neuroscience, 10(3), 199-210. https://doi.org/10.1038/nrn2576

Irwin, M. R., Olmstead, R., Carroll, J. E. (2016). Sleep Disturbance, Sleep Duration, and Inflammation: A Systematic Review and Meta-Analysis of Cohort Studies and Experimental Sleep Deprivation. Biological Psychiatry, 80(1), 40-52. https://doi.org/10.1016/j.biopsych.2015.05.014

Jniene, A., Errguig, L., El Hangouche, A. J., Rkain, H., Aboudrar, S., El Ftouh, M., Dakka, T. (2019). Perception of sleep disturbances due to bedtime use of blue light-emitting devices and its impact on habits and sleep quality among young medical students. BioMed research international, 1-8, 7012350. https://doi.org/10.1155/2019/7012350 
Keyes, C. (2006). Subjective well-being in mental health and human development research worldwide: An introduction. Social Indicators Research, 77(1), 1-10. http://doi.org/10.1007/s11205-005-5550-3

Krystal, A. D., Edinger, J. D. (2008). Measuring sleep quality. Sleep medicine, 9, S10-S17. https://doi.org/10.1016/S1389-9457(08)70011-X

MacKean, G. (2011, June). Mental health and well-being in post-secondary education settings. CACUSS pre-conference workshop on mental health, Toronto.

Malta, D. C., Gomes, C. S., Szwarcwald, C. L., Barros, M. B. A., Silva, A. G., Prates, E. J. S., Machado, Í. E., Souza Júnior, P. R. B., Romero, D. E., Lima, M. G., Damacena, G. N., Azevedo, L. O., Pina, M. F., Werneck, A. O., Silva, D. R. P. (2020). Distanciamento social, sentimento de tristeza e estilos de vida da população brasileira durante a pandemia de Covid-19. Saúde em Debate, 44(4), 177-190. https://doi.org/10.1590/0103-11042020e411

Malta, D. C., Gomes, C.S., Silva, A. G., Sá, A.C.M.G.N., Prates, E. J. S., Freitas, M. I. F., Machado, I.E., Barros, M. B.A., Souza Júnior, P. R. B., Romero, D. E., Damacena, G. N., Azevedo, L. O., Szwarcwald, C.L. (2021). Mudanças no estilo de vida em adultos durante a pandemia de COVID-19 em Minas Gerais. In A. R. Da Silva (organizador), Enfermagem e Covid-19: Desafios e Perspectivas (pp. 35-49). Atena.

Marane, S. S. G. (2016). Influência Dietética na Química Cerebral [Trabalho de Conclusão de Curso, Universidade Estadual Paulista]. Repositório Institucional UNESP. https://repositorio.unesp.br/bitstream/handle/11449/140209/000864950.pdf?sequence=1\&isAll owed $=\mathbf{y}$

Marins, L., Franchini, M., Polese, J. F., Guandalini, V., Coitinho, J. B., Araújo, M. T. M. (2020). Dieta rica em triptofano pode influenciar a qualidade do sono em diferentes fases da vida. DEMETRA: Alimentação, Nutrição \& Saúde, 15, 44327. https://doi.org/10.12957/demetra.2020.44327

Matias, T. S., Dominski, F. H. (2020). The COVID-19 pandemic challenges physical activity with two emerging paradigms. Revista Brasileira de Atividade Física \& Saúde, 25, 1-6. https://doi.org/10.12820/rbafs.25e0113

Marelli, S., Castelnuovo, A., Somma, A., Castronovo, V., Mombelli, S., Bottoni, D., Leitner, C., Fossati, A., Ferini-Strambi, L. (2021). Impact of COVID-19 lockdown on sleep quality in university students and administration staff. Journal of Neurology, 268(1), 8-15. https://doi.org/10.1007/s00415-020-10056-6

Mello, M.T. (2013). Psicobiologia do Exercício. São Paulo: Editora Atheneu.

Microsoft. (2007). Microsoft Office Excel 2007 [Software de computador]. Microsoft. https://www.microsoft.com/pt-pt/microsoft-365/previous-versions/microsoft-excel-2007

Ministério da Saúde (2021). Guia de Atividade Física para a População Brasileira. Brasília, Brasil. Secretaria de Atenção Primária à Saúde. Departamento de Promoção da Saúde. http://bvsms.saude.gov.br/bvs/publicacoes/guia_atividade_fisica_populacao_brasileira.pdf

Mohajeri, M. H., Wittwer, J., Vargas, K., Hogan, E., Holmes, A., Rogers, P. J., Goralczyk, R., Gibson, E. L. (2015). Chronic treatment with a tryptophan-rich protein hydrolysate improves emotional processing, mental energy levels and reaction time in middle-aged women. British Journal of Nutrition, 113(2), 350-365. https://doi.org/10.1017/S0007114514003754 
Nelson, D.L., Cox, M.M. (2014). Princípios de Bioquímica de Lehninger (6 ed). Porto Alegre: Artmed.

Nesse, R. M., Williams, G. C. (1997). Por que adoecemos? A nova ciência da medicina darwinista. Rio de Janeiro: Campus.

Nogueira, M. J. C. (2017). Saúde Mental em Estudantes do Ensino Superior: Fatores Protetores e Fatores de Vulnerabilidade. [Tese de Doutorado em Enfermagem], Lisboa, Portugal. https://repositorio.ul.pt/bitstream/10451/28877/1/ulsd730773_td_Maria_Nogueira.pdf

Norbury, R., Evans, S. (2019). Time to think: Subjective sleep quality, trait anxiety and university start time. Psychiatry Research, 271, 214-219. https://doi.org/10.1016/j.psychres.2018.11.054

Ohayon, M., Wickwire, E. M., Hirshkowitz, M., Albert, S. M., Avidan, A., Daly, F. J., Dauvilliers, Y., Ferri, R., Fung, C., Gozal, D., Hazen, N., Krystal, A., Lichstein, K., Mallampalli, M., Plazzi, G., Rawding, R., Scheer, F. A., Somers, V., Vitiello, M. V. (2017). National Sleep Foundation's sleep quality recommendations: First report. Sleep Health, 3(1), 6-19. https://doi.org/10.1016/i.sleh.2016.11.006

Ornellas, L. H. (2007). Técnica dietética: seleção e preparo de alimentos. (8 ed.). Atheneu.

Pan, H. (2020). A Glimpse of University Students' Family Life Amidst the COVID-19 Virus. Journal of Loss and Trauma, 25(6-7), 594-597. https://doi.org/10.1080/15325024.2020.1750194

Pérez-Fuentes, M. C., Molero Jurado, M. M., Martínez, Á. M., \& Gázquez Linares, J. J. (2020). Threat of COVID-19 and emotional state during quarantine: Positive and negative affect as mediators in a cross-sectional study of the Spanish population. PLOS ONE, 15(6), Artigo e0235305. https://doi.org/10.1371/journal.pone.0235305

Peuhkuri, K., Sihvola, N., Korpela, R. (2012). Dietary factors and fluctuating levels of melatonin. Food \& nutrition research, 56(1), 1-9, 17252. https://doi.org/10.3402/fnr.v56i0.17252

Peuhkuri, K., Sihvola, N., Korpela, R. (2012). Diet promotes sleep duration and quality. Nutrition Research, 32(5), 309-319. https://doi.org/10.1016/j.nutres.2012.03.009

Rhodes, R. E., Martin, A. D., Taunton, J. E. (2001). Temporal relationships of self-efficacy and social support as predictors of adherence in a 6 -month strength-training program for older women. Perceptual and motor skills, 93(3), 693-703.https://doi.org/10.2466/pms.2001.93.3.693

Richter, S. A., Schilling, L. B., Camargo, N. F., Taurisano, M. R. G., Fernandes, N. F., Wearick-Silva, L. E., \& Nunes, M. L. (2020). Como a quarentena da COVID-19 pode afetar o sono das crianças e adolescentes?. Residência Pediátrica, https://cdn.publisher.gn1.link/residenciapediatrica.com.br/pdf/rp130521a01.pdf

Rodriguez-Ayllon, M., Cadenas-Sánchez, C., Estévez-López, F., Muñoz, N. E., Mora-Gonzalez, J., Migueles, J. H., Molina-García, P., Henriksson, H., Mena-Molina, A., Martínez-Vizcaíno, V., Catena, A., Löf, M., Erickson, K. I., Lubans, D. R., Ortega, F. B., \& Esteban-Cornejo, I. (2019). Role of Physical Activity and Sedentary Behavior in the Mental Health of Preschoolers, Children and Adolescents: A Systematic Review and Meta-Analysis. Sports Medicine, 49(9), 1383-1410. https://doi.org/10.1007/s40279-019-01099-5

Santos, A. P. R. (2021). Impacto da Pandemia da COVID-19 na Qualidade de Vida, Nível de Atividade Física e Saúde Mental de Jovens Universitários. [Dissertação de Mestrado] , Programa de Pós- graduação em Hebiatria, Universidade de Pernambuco, Campus Camaragibe, Recife, Brasil. https://w2files.solucaoatrio.net.br/atrio/upe- 
hebiatria upl/THESIS/104/diss.ana santos.2021 ana paula rodrigues dos santos 202111 08080622628.pdf

Saper, C. B., Lu, J., Chou, T. C., Gooley, J. (2005). The hypothalamic integrator for circadian rhythms. Trends in Neurosciences, 28(3), 152-157. https://doi.org/10.1016/j.tins.2004.12.009

Saraiva, E. M., Fortunato, J. M. S., Gavina, C. (2013). Oscilações do Cortisol na Depressão e Sono/Vigília. Revista Portuguesa de Psicossomática, 7 (1-2), 189-100. https://www.redalyc.org/pdf/287/28770207.pdf

Schwartz, M. D., Kilduff, T. S. (2015). The Neurobiology of Sleep and Wakefulness. Psychiatric Clinics of North America, 38(4), 615-644. https://doi.org/10.1016/j.psc.2015.07.002

Seal, C. J., Nugent, A. P., Tee, E. S.,Thielecke, F. (2016). Whole-grain dietary recommendations: the need for a unified global approach. British Journal of Nutrition, 115(11), 2031-2038. DOI: 10.1017/S0007114516001161. https://pubmed.ncbi.nlm.nih.gov/27082494/

Shabbir, F., Patel, A., Mattison, C., Bose, S., Krishnamohan, R., Sweeney, E., Sandhu, S., Nel, W., Rais, A., Sandhu, R., Ngu, N., \& Sharma, S. (2013). Effect of diet on serotonergic neurotransmission in depression. Neurochemistry International, 62(3), 324-329. https://doi.org/10.1016/j.neuint.2012.12.014

Sidor, A., Rzymski, P. (2020). Dietary Choices and Habits during COVID-19 Lockdown: Experience from Poland. Nutrients, 12(6), 1657. https://doi.org/10.3390/nu12061657

Silva, E. D. S. M., Ono, B. H. V. S., Souza, J. C. (2020). Sleep and immunity in times of COVID-19. Revista Da Associação Médica Brasileira, 66(Suppl 2), 143-147. https://doi.org/10.1590/18069282.66.S2.143

Silva, R. M. D., Goulart, C. T., Guido, L. D. A. (2018). Evolução histórica do conceito de estresse. Revista de Divulgação Científica Sena Aires, 7(2), 148-156. http://revistafacesa.senaaires.com.br/index.php/revisa/article/viewFile/316/225

Silva, L. G. (2020). Neurociência Nutricional: Aspectos Nutricionais na Saúde Mental [Trabalho de Conclusão de Curso, Centro Universitário Unifacvest] Banco de TCC Unifacvest. https://www.unifacvest.edu.br/assets/uploads/files/arquivos/8d427-godinho-I.s.-neurociencianutricional-aspectos-nutricionais-na-saude-mental.-unifacvest-lages,-tcc-defendido-em-08-dejulho-de-2020..pdf

Silveira, J. P. D. (2021). Estilo de vida em universitários do sul do brasil e a influência da pandemia da COVID-19. [Trabalho de Conclusão de Curso para graduação]. Repositório Institucional Universidade Federal de Santa Catarina. https://repositorio.ufsc.br/handle/123456789/228471

Stanton, R., To, Q. G., Khalesi, S., Williams, S. L., Alley, S. J., Thwaite, T. L., Fenning, A. S., Vandelanotte, C. (2020). Depression, Anxiety and Stress during COVID-19: Associations with Changes in Physical Activity, Sleep, Tobacco and Alcohol Use in Australian Adults. International Journal of Environmental Research and Public Health, 17(11), Artigo 4065. https://doi.org/10.3390/ijerph17114065

Szwarcwald, C. L., Bastos, F. I., Esteves, M. A. P. (2005). State of animus among Brazilians: Influence of socioeconomic context? Cadernos de Saúde Pública, 21(1), S33-S42. https://doi.org/10.1590/S0102-311X2005000700005 
Tasso, A. F., Hisli Sahin, N., San Roman, G. J. (2021). COVID-19 disruption on college students: Academic and socioemotional implications. Psychological Trauma: Theory, Research, Practice, and Policy, 13(1), 9-15. https://doi.org/10.1037/tra0000996

Tempesta, D., Socci, V., De Gennaro, L., \& Ferrara, M. (2018). Sleep and Emotional Processing. Sleep Medicine Reviews, 40, 183-195. https://doi.org/10.1016/j.smrv.2017.12.005

THE WHOQOL GROUP (1995). The World Health Organization quality of life assessment (WHOQOL): position paper from the World Health Organization. Social Science and Medicine. https://www.sciencedirect.com/science/article/abs/pii/027795369500112K

Torres, A. (2012). Melatonina para dormir melhor: os melhores alimentos. Andreia Torres Nutricionista. https://andreiatorres.com/blog/2012/07/31/melatonina-para-dormir-melhor-osmelhores-alimentos

Valim, C. M. S. C., Teixeira, F. C. F., Soares, L. C. B (2017). ESTILO DE VIDA E SONO: REFLEXOS DURANTE A VIDA. In F. P. S. Costa, L. C. B. Soares, V. C. Kunz (Orgs.). Estilo De Vida Saudável: uma questão de escolha (pp. 27-38). São Paulo, SP: Clube de Autores.

Verger, P., Combes, J.-B., Kovess-Masfety, V., Choquet, M., Guagliardo, V., Rouillon, F., PerettiWattel, P. (2009). Psychological distress in first year university students: Socioeconomic and academic stressors, mastery and social support in young men and women. Social Psychiatry and Psychiatric Epidemiology, 44(8), 643-650. https://doi.org/10.1007/s00127-008-0486-y

Voitsidis, P., Gliatas, I., Bairachtari, V., Papadopoulou, K., Papageorgiou, G., Parlapani, E., Syngelakis, M., Holeva, V., Diakogiannis, I. (2020). Insomnia during the COVID-19 pandemic in a Greek population. Psychiatry research, 289, 113076. https://doi.org/10.1016/j.psychres.2020.113076

Walker, M. P. (2009). The Role of Sleep in Cognition and Emotion. Annals of the New York Academy of Sciences, 1156(1), 168-197. https://doi.org/10.1111/i.1749-6632.2009.04416.x

World Health Organization. (2020). Emergency Committee. WHO Director - General's opening remarks at the media briefing on COVID-19. Genebra: World Health Organization. https://www.who.int/director-general/speeches/detail/who-director-general-s-opening-remarksat-the-media-briefing-on-covid-19---11-march-2020

Werneck, A. O., Silva, D. R., Malta, D. C., Lima, M. G., Souza-Júnior, P. R. B., Azevedo, L. O., Barros, M. B. A., Szwarcwald, C. L. (2020). The mediation role of sleep quality in the association between the incidence of unhealthy movement behaviors during the COVID-19 quarantine and mental health. Sleep Medicine, 76, 10-15. https://doi.org/10.1016/..sleep.2020.09.021

Zanello, D. R. P. (2012). Efeitos Do L-Triptofano Sobre Ansiedade, Compulsão e Escolha Alimentar. [Tese de graduação, Centro Universitário de Brasília] CEUB Educação Superior. https://repositorio.uniceub.br/jspui/bitstream/235/7287/1/Diogo\%20Rabelo\%20de\%20Paula\%2 0Zanello.pdf

Zhao, M., Tuo, H., Wang, S., Zhao, L. (2020). The Effects of Dietary Nutrition on Sleep and Sleep Disorders. Mediators of Inflammation, 2020, 1-7, Artigo 3142874. https://doi.org/10.1155/2020/3142874 